\title{
Music Listening for Supporting Adolescents' Sense of Agency in Daily Life
}

\author{
Suvi Helinä Saarikallio*, William M. Randall and Margarida Baltazar
}

Department of Music, Art and Culture Studies, University of Jyväskylä, Jyväskylä, Finland

Sense of agency refers to the ability to influence one's functioning and environment, relating to self-efficacy, and wellbeing. In youth, agency may be challenged by external demands or redefinition of self-image. Music, having heightened relevance for the young, has been argued to provide feelings of self-agency for them. Yet, there is little empirical research on how music impacts adolescents' daily sense of agency. The current study investigated whether music listening influences adolescents' perceived agency in everyday life and which contextual determinants would explain such an influence. Participants were 44 adolescents (48\% female, 36\% with training in music, mean age 14), recruited through local schools. The mobile Experience Sampling app

OPEN ACCESS

Edited by:

Evangelos Himonides, University College London,

United Kingdom

Reviewed by:

Graça Maria Boal-Palheiros, Instituto Politécnico do Porto,

Portugal

Makiko Sadakata, Radboud University Nijmegen,

Netherlands

*Correspondence:

Suvi Helinä Saarikallio suvi.saarikallio@jyu.fi

Specialty section:

This article was submitted to Performance Science, a section of the journal

Frontiers in Psychology

Received: 19 August 2019 Accepted: 09 December 2019 Published: 08 January 2020

Citation:

Saarikallio SH, Randall WM and Baltazar M (2020) Music Listening for Supporting Adolescents' Sense

of Agency in Daily Life.

Front. Psychol. 10:2911. doi: 10.3389/fpsyg.2019.02911
MuPsych was used to collect brief self-reports of personal music listening experiences during daily life. This method assessed the change in the listener's perceived control over both their emotional states (internal agency), and their external environment (external agency), over 5 min of music listening. Also measured were changes in mood states, and contextual variables (social situation, concurrent activity, and reason for listening). The impact of music on the sense of agency was analyzed using multilevel structural equation modeling. There was no general increase of agency across all music episodes, but agency fluctuations were determined by specific contextual factors. External agency change was predicted negatively by changing environments, while internal agency change was predicted by initial mood and various reasons for listening, including for enjoyment, coping, and enhancing current mood state. Our findings confirmed the plasticity and situational embeddedness of the sense of agency. Music indeed can support agency, but the impact is dependent on a range of situational factors. Sense of agency can be seen as a health resource and significant part of youth development, and current findings provide new insight into when and by which conditions such affordance is likely to be employed.

Keywords: sense of agency, music listening, everyday life, adolescents, experience sampling

\section{INTRODUCTION}

\section{Agency: Concept and Definition}

Human agency is a core concept in social cognitive theory (Bandura, 1982, 1989, 2006), which posits that people are self-organizing, proactive, self-regulating, and self-reflecting (Bandura, 2006, p. 164). Agency is defined as the ability to influence one's environment and functioning (Bandura, 1982, 1989). Notwithstanding, individuals are not totally detached from their surroundings; 
instead, there is a reciprocal causation process, where personal and environmental determinants operate. Agency can, thus, be conceived as "embedded and situated, yet also emergent within historical sociocultural contexts, which in turn are nested in the biological and physical world" (Martin et al., 2003, p.133). Consequently, agency is a plastic, changing, and negotiable stated (as opposed to a trait or competence), reliant on context-bound, interdependent, and dynamic processes (Esser et al., 2016).

Importantly, how successfully people can influence, control, and negotiate events that affect their lives varies from moment to moment, but so do the beliefs in their capability of action (Bandura, 1995). These beliefs are commonly termed as "self-efficacy" (Bandura, 1982), and they influence behavior and its outcomes through several cognitive (e.g., prediction of success/failure), motivational (e.g., resilience), and affective processes (e.g., stress). According to the models of human agency and self-efficacy, every motivator of action and change has in its foundation the core belief that one has the power to effect changes by one's actions. Simply put, without beliefs of self-efficacy, people do not act on their surroundings or own states. Beliefs of efficacy act as vital forces supporting motivation, well-being, and personal accomplishment in all areas of life (Pajares, 2005, p.339). Indeed, several studies have consistently shown that efficacy beliefs contribute to, for example, smoke-cessation (Schnoll et al., 2011), adherence to healthy behavior (Strecher et al., 1986), recovery from traumatic situations (Bosmans and van der Velden, 2015), and lower levels of depression (Sawatzky et al., 2012).

In sum, agency reveals itself through intentional acts that can produce different outcomes. This can be the case of listening to music: the act of music listening in a given moment and context immediately changes the situation - be it in terms of soundscapes, affective states, connectedness, meanings... (DeNora, 1999, 2000, 2013; Lincoln, 2005; Krueger, 2011, 2018; Skånland, 2013; O'Neill, 2017). In this paper, we conceptualize musical agency as the use of music (in its different genres, behaviors, and contexts...) to capitalize, exercise, and regain agency and sense of agency (similar to "aesthetic agency," DeNora, 2000, 2001). ${ }^{1}$

\section{Agency in Adolescence}

In many aspects, adolescence is defined by the individuals' trajectory toward their empowerment as agents who can create and control several aspects of their world (Beyers et al., 2003; Gowers, 2005). As adolescents increase their independence, form their identity, and work on their emotional experiences, they are faced with the opportunity to become self-sufficient agents. During adolescence, agency is practiced throughout almost every dimension of life and a personal growth through mastery is observed. The adolescents' sense of efficacy is strengthened by learning how to successfully deal with pressing issues (such as vocational definition, sexuality, family, and affect regulation), accompanied by vicarious experiences (such as modeling of a peer's behavior), persuasive information from others (such as

\footnotetext{
${ }^{1}$ Different from "musical agency" used in the context of music education by Wiggins (2016) as a "sense that they can initiate and carry out their own musical ideas and ideas about music."
}

verbal encouragement), and positive physiological feedback (such as states of arousal appraised as confidence) (Bandura, 1977).

Importantly, the sense of agency has been pointed out as a key variable to understand the paths through adolescence into adulthood (Bandura, 1995; Pajares and Urdan, 2006). Thus, it closely relates to several aspects of adolescents' healthy development and adaptation. Agency is part of the development of behavioral regulation: adolescents' self-regulation has been for instance defined in terms of three agentic behaviors: selection (choosing opportunities that match with one's sense of self and personal potential), optimization (refining one's resources to reach goals) and compensation (being able to "change course" if resources fail) (Lerner et al., 2001). Agency also closely relates to identity formation: a composite measure of agency, consisting of self-esteem, purpose in life, ego strength, and internal locus of control, has been found to positively relate to identity achievement and negatively to identity diffusion (Côté and Schwartz, 2002). Similarly, internal locus of control has been shown to relate to identity achievement while external locus of control relates to identity statuses of moratorium, foreclosure, and diffusion (Lillevoll et al., 2013). It has been argued that the increased pressure in Western societies for each young person to find their own, personal, path to adulthood places agency, self-determination, and self-directedness in a heightened role: those who are able to capitalize on the breadth of opportunities are likely to flourish but those who are unable to exercise personal agency at this stage may find their developmental period particularly distressing (Schwartz et al., 2005). In line with these, the Self-Determination Theory stresses autonomy and competence as essential features for adaptive development and wellbeing (Ryan and Deci, 2000).

\section{Music, Agency, and Self-Efficacy}

A well-established body of literature documents the role of music in youth development (McFerran, 2011; ter Bogt et al., 2012; Miranda, 2013). There is evidence showing that musical behaviors foster the adolescent's ability to cope with the challenges that matter the most during this developmental stage: identity definition (North and Hargreaves, 1999; North et al., 2000; Hense and McFerran, 2017), connection with peers (Selfhout et al., 2009; Papinczak et al., 2015; ter Bogt et al., 2017), affect regulation (Saarikallio and Erkkilä, 2007; McFerran and Saarikallio, 2014; Leipold and Loepthien, 2015), and shaping of agency (Laiho, 2004; Gold et al., 2011). It has been argued that music occupies such an important place in adolescents' lives precisely because of the developmental functions it serves (Schwartz and Fouts, 2003; Laiho, 2004; Miranda, 2013). In terms of serving as a personal resource for agency music holds particular potential for the young, as Saarikallio (2019b) points out: "Music is the kids" own world, their playground and kingdom, in which they can shout and be silly, to be fragile and in search of themselves, and make their own, personal, choices."

As argued by Krueger (2011), music is perceived from birth as a structure that affords possibilities - for constructing and regulating emotions, for expressing and communicating, for shaping relationships and situations. Children's play, symbols, drawings, and music uses are not only contemplative, but mainly 
participatory, engaged, and active-i.e., agentic (Karlsen, 2011; Bonsdorff, 2017; Rissanen, 2017; Kuuse, 2018). Through the use of these esthetic resources, children develop from early ages their agency and sense of self-efficacy. In the case of music, it has been observed that there is a constant, informal learning in everyday life (Batt-Rawden and DeNora, 2005), supported by music listening, reflection, and narrative, that create memories, patterns, meanings, and gateways between the individual and the social surroundings. Learning how music can be used empowers the individual to act on their own affective states, wellbeing, health, and agency modes (DeNora, 2000, 2001; Skånland, 2013).

\section{Music-Fostered Agency and Wellbeing}

Seeking and exploring the sense of agency through music seems to be particularly relevant for individuals that are either developing their agency (i.e., youth) or experiencing a reduction in their ability to control their actions and/or environment (e.g., due to illness or challenging personal situations) (Magee, 2017). Batt-Rawden and colleagues have conducted studies with individuals dealing with chronic affective or physical illnesses (Batt-Rawden and DeNora, 2005; Batt-Rawden et al., 2005; BattRawden and Tellnes, 2011). Their data show that, by reflecting on their music uses and learning self-care, the participants increased their sense of control and agency. When using music to cope with pain or stressful medical interventions, control and agency have also appeared to matter significantly: the beneficial effects of music have been reported to be especially visible when the participants could choose their own music to listen to (Mitchell and Macdonald, 2006; Pothoulaki et al., 2008; Bernatzky et al., 2011; Jiang et al., 2013). In a feasibility study of a brief music-based intervention for adolescents, McFerran et al. (2018) observed that the sense of agency was key for the participants: after the intervention, the young participants reported an increased awareness of their position as agents who can utilize the affordances of music to reduce distress and promote their own development.

Sense of agency has been identified as a defining element in music usages and their role on social-emotional health (Saarikallio, 2017, 2019a,b; Saarikallio and Baltazar, 2018). In the conceptual model of health-relevant competencies in music, Saarikallio $(2017,2019$ a) argues that engaging in musical behaviors can foster emotional health when the emotions expressed, evoked, and regulated through music are surrounded by (a) self-reflective awareness and (b) sense of self-control and agency. Concerning musical self-enhancement, Elvers (2016) proposed a framework according to which there are three main musical experiences bolstering positive self-evaluations: induction of empathy (through identification with the music, self/other merging, and self-confirmation), promotion of social cohesion (through rhythmic entrainment and reinforcement of a cultural worldview and sense of social belonging), and pleasure (through the induction of positive affect, default mode networkactivation, and self-referential emotions). According to Elvers, this framework encompasses "the kind of musical experiences that elicit positive affect related to the self, that induce feelings of power and control, that promote positive self-evaluations, and ultimately promote self-esteem" (Elvers, 2016, p. 3). In this line of thought, the use of music to increase the sense of agency and beliefs of efficacy can be seen as one way of musical self-enhancement.

\section{Aims of the Current Study}

Despite the breadth of research arguing that music holds potential for serving as a resource for agency in adolescents' lives, there is little empirical work on the impacts of music listening to adolescents' sense of agency. This study was designed to investigate how music listening would relate to the everyday fluctuations of adolescents' sense of agency.

Following our definition of agency as a plastic and contextbound ability to influence one's environment and functioning, we placed particular focus on exploring the unfolding situational aspects of daily life as the context in which the impacts of music on agency would occur. We addressed agency both in terms of internal control of one's feelings and in terms of one's perceived sense of having control over the external environment (labeled in this paper as internal and external agency). We chose to focus on music listening in contrast to active music making, because that is an activity available practically for all adolescents in the multitude of their everyday life events and environments. Finally, as the majority of current research on music and agency is constituted of theoretical propositions, we decided to provide empirical evidence through measuring changes in agency as a function of daily music listening. Although it has not been observed empirically yet, we expected to find differences in perceived agency after an episode of music listening.

Firstly, we expected to observe a general increase in the self-perceived sense of agency (in terms of both internal and external control) across the episodes of music listening. Secondly, we explored whether the impacts of music listening on the sense of agency would depend on specific contextual factors including simultaneous activities, presence of other people, current mood and energy level, and reasons for music listening at the given moment. Thirdly, we expected changes in both internal and external agency to correlate with changes in valence, with increased sense of agency correlating positively with mood improvement.

\section{MATERIALS AND METHODS}

\section{Participants}

Participants were recruited through middle schools within the Jyväskylä sub-region of Finland. The research team first contacted the rectors and music teachers of the schools, visited the schools, and provided information about the study to the students as part of their music classes. Students who volunteered downloaded the app with assistance provided by a video instruction and/or the researchers directly. Participants were required to have a mobile phone with the Android mobile operating system, that they used for personal music listening. The sample consisted of 44 year 7 and 8 students (age $M=13.67, S D=1.87$ ), all native to Finland, with a mix of both girls and boys ( $47.7 \%$ female). The majority of participants reported no formal practical music training (36.4\% 
reported at least 1 year of training). Participation was incentivized through a draw to win Spotify subscriptions.

\section{Materials}

All research materials were presented through the MuPsych app, which was originally developed and tested by Randall and Rickard (2013), with an updated version developed at the University of Jyväskylä. The app collected data through two means: music experience sample reports (ESRs), and surveys. All items were presented in Finnish. A total of 327 music listening episodes were reported $(M=7.43, S D=3.66)$.

Music experience sample reports were presented immediately when the participant listened to any music on their phone. The initial screen assessed current affective state, with responses given on two 7-point slider scales: the first titled "Mood," with labels for "Negative," "Neutral" (center) and "Positive"; and the second titled "Energy," labeled from "Very low" to "Very high." These variables were recorded as "initial valence" and "Initial arousal," respectively. These two dimensions have been demonstrated to be efficient and reliable measures of music induced emotion, explaining a high proportion of variance (Vuoskoski and Eerola, 2011; Thoma et al., 2012). Participants additionally selected one distinct mood that best matched their current feelings and rated how intensely ("Not at all" to "Very") they felt that mood (named "Mood Intensity"). The following screen consisted of two 7-point slider scales, which were designed to assess the sense of agency: For the external component of agency - a sense of being in charge of the environment - a question was phrased: "Do you feel that the situation is in your control?" (from "Not at all" to "Completely"); and for the internal component of agency - focusing on sense of being in charge of one's feelings - a question was phrased "Is your mood the way you want it to be?" (from "Not at all" to "Completely"). The variables were labeled as "External Agency" and "internal agency," respectively. The following three screens used a list-response format to assess who the listener was with (Listeners), where they were (Location), and what they were doing while listening (Activity).

If music was still playing on the phone after a period of $5 \mathrm{~min}-$ as automatically determined by the app - a second series of screens was presented. The first of these screens assessed the same continuous variables measured at the start of listening (Valence, Arousal, Mood Intensity, External Agency, and internal agency), to determine how these changed over the listening episode. The second screen included questions related to the music, on five 7-point slider scales: Mood of the music (subjectively perceived emotion of the music, as distinct from the induced emotion of the listener; Negative - Neutral - Positive), the Energy of the music (Low Energy - High Energy); "How much attention are you paying to the music?" (Attention; None - Complete); "How much are you enjoying this music?" (Enjoyment; Not at all - Very much); and "How familiar are you with this music?" (Familiarity; Not at all - Very familiar). These five music questions were included to provide an overview about how the listener perceived the music at the given episode. The final screens of the music ESR used a branching list-response format to assess the main reason for listening. These reasons were categorized as: For current activity; For entertainment/enjoyment; To relax/calm down; To focus on the Music; For boredom/habit; To cope with a situation; For thinking/reflecting; To raise/boost energy; To enhance my current mood; To diminish my current mood; and To maintain my current mood.

The surveys presented within MuPsych were a series of psychometric scales to assess individual variables, which could be completed at any time. Participants were asked to report their gender and how many years of formal practical music training they had received. They also filled in the 44-item version of the Big Five personality Inventory (John and Srivastava, 1999). Previous research has demonstrated that scales presented within MuPsych produce similar Cronbach alpha scores to those published from the standard questionnaires (Randall and Rickard, 2013).

\section{Procedure}

Prior to the study, an ethics approval was applied for and granted by the University of Jyväskylä Ethical Committee. Information statements were sent to parents of all potential participants through an internal school system, before the participants themselves were contacted during their music classes. They were presented with details about the research and instructed to install the MuPsych app on their mobile phone. All elements of the study were presented through the app, including an information statement, music ESRs, and all surveys. Music ESRs were presented when any music was played on the phone, however, once one had been completed, no more were presented for a period of $4 \mathrm{~h}$, to avoid respondent fatigue. Surveys were presented within the app and could be completed at any time of convenience. This data collection continued for a period of 1 week, after which no more ESRs were presented.

\section{Data Analyses}

Two separate approaches were utilized to analyze the data: aggregate scores on the participant level were used to determine changes in agency overall and across different listening reasons and contexts; and a multilevel model was used to consider context variables, with musical experiences nested within listeners. For the first approach, aggregate scores were created for each individual participant, producing means for valence, arousal, mood intensity, internal, and external agency. This approach is recommended for ESM (Hektner et al., 2007), and has been utilized in previous ESM studies of music use (Randall et al., 2014). Paired-samples $t$-tests were then performed to determine if music listening produced any significant changes in these aggregate scores. The second approach involved the implementation of a multilevel structural equation model (SEM), using Mplus software (version 7.4: Muthén and Muthén, 2015). A total of 327 musical experiences were included in the model, clustered within 44 listeners. This multilevel approach accounted for both the variance in emotional outcomes due to variation amongst musical experiences, and the variance due to variation amongst individual listeners. Maximum likelihood estimation with robust standard errors (MLR) was used, with an accelerated expectation-maximization (EMA) optimization algorithm. Pearson correlation was used to test the relatedness of agency change with valence, arousal, and mood intensity change. 


\section{RESULTS}

\section{Aggregate Analysis}

To determine if any overall changes in External Agency, internal agency, Valence, Arousal, or Mood Intensity were produced from music listening, repeated-measures $t$-tests were performed on the aggregate participant scores. These tests revealed no significant changes, with the details reported in Table 1. Also on the aggregate level, no significant effect of gender was found on either external $(p=0.239)$ or INTERNAL AGENCY change $(p=0.371)$, and no significant correlations were observed between these agency measures and BFI personality scales or years of musical training. Aggregate level frequencies revealed that $91 \%$ of listening episodes were solitary, $58.11 \%$ were at home, $20.42 \%$ traveling, and $17.44 \%$ at school and the most frequent activity was "Nothing/waiting" $11.72 \%$, followed by $11.15 \%$ "In a car," $11.02 \%$ "Focussed listening," and 10.68\% "Studying." The most frequently reported reasons for listening were "For entertainment/enjoyment" (16.42\%), "For current activity" (15.32\%), "For boredom/habit" (14.03\%), and "To relax/calm down” (12.77\%).

\section{Multilevel Analysis}

Correlations between changes in External Agency, internal agency, Valence, Arousal, and Mood Intensity are displayed in Table 2. This shows significant positive correlations between all variables, with the strongest between internal agency change and Valence change. In line with the hypothesis, valence change and agency change were positively correlated.

A multilevel structural equation model was constructed to assess the interaction of all measured variables, with all significant predictors presented in Table 3 (with the effects of initial agency states on their respective changes in agency removed). This model produced a standardized root mean square residual (SRMR) of 0.038 on the musical experience level (with values of less than 0.08 generally considered a good fit: $\mathrm{Hu}$ and Bentler, 1999).

TABLE 1 | Overall changes in agency and affective variables during music listening.

\begin{tabular}{lccccc}
\hline & $\begin{array}{c}\text { Mean } \\
(\mathbf{0} \text { } \mathbf{i n})\end{array}$ & $\begin{array}{c}\text { Mean } \\
(\mathbf{5} \text { } \mathbf{i n})\end{array}$ & $\begin{array}{c}\text { Mean } \\
\text { difference }\end{array}$ & $\boldsymbol{t}$ & $\boldsymbol{p}$ \\
\hline External agency & 1.879 & 1.975 & 0.096 & 1.184 & 0.246 \\
Internal agency & 0.985 & 1.135 & 0.150 & 1.628 & 0.115 \\
Valence & 1.238 & 1.334 & 0.096 & 0.933 & 0.359 \\
Arousal & 0.213 & 0.429 & 0.217 & 1.901 & 0.068 \\
Mood intensity & 1.697 & 1.418 & -0.280 & -2.457 & $0.020^{*}$ \\
\hline
\end{tabular}

*is significant at point 0.05 .

TABLE 2 | Correlations between agency change variables and affective change variables.

\begin{tabular}{lcccc}
\hline & $\begin{array}{c}\text { Internal } \\
\text { agency } \\
\text { change }\end{array}$ & $\begin{array}{c}\text { Valence } \\
\text { change }\end{array}$ & $\begin{array}{c}\text { Arousal } \\
\text { change }\end{array}$ & $\begin{array}{c}\text { Mood } \\
\text { intensity } \\
\text { change }\end{array}$ \\
\hline External agency change & $0.197^{* *}$ & $0.186^{* *}$ & $0.147^{* *}$ & 0.017 \\
Internal agency change & - & $0.293^{* *}$ & $0.142^{* *}$ & $-0.105^{*}$ \\
\hline
\end{tabular}

*is significant at point 0.05 and **is significant at point 0.01 .
These results in Table 3 reveal two weak negative predictors for External Agency change: the activities of walking $(\beta=-0.112$; frequency of walking experiences $=5.11 \%$ ), and on transport ("On bus/train/plane"; $\beta=-0.080$; frequency $2.18 \%$ ). internal agency change was positively predicted by initial valence of the listener $(\beta=0.306)$, the reason "Enjoyment" ("For entertainment/enjoyment"; $\beta=0.200$; frequency $16.42 \%$ ), the reason "To cope" ("To cope with a situation"; $\beta=0.153$; frequency $4.35 \%$ ), the reason "Enhance mood" ["To feel more (of my selected mood state)"; $\beta=0.152$; frequency $2.75 \%$ ], listening alone ( $\beta=0.128$; frequency $91.00 \%)$, and negatively predicted by the activity of studying ( $\beta=-0.113$; frequency $10.68 \%)$.

\section{DISCUSSION}

The analysis of the music listening experiences as a whole revealed that changes in the sense of agency are not transversal to all episodes. However, fluctuations in agency were observed within the episodes and particular context factors and reasons for listening were identified as explaining the modulations in perceived agency. These results are in line with both music literature and agency literature. The former informs us that there is a plethora of contextual factors that shape the usages and related affective impact of music in everyday life listening (Randall and Rickard, 2017a,b), and the latter posits that the sense of agency is embedded, context-bound, plastic, and malleable (Martin et al., 2003; Esser et al., 2016). The findings of the current study confirm that the relationship of music and perceived agency is intrinsically embedded in the multifaceted nature of our daily experiences, dependent on specific contextual variables. Additionally, the current results confirm the feasibility of measuring fluctuations in perceived agency, even after a short period of music listening ( $5 \mathrm{~min}$ ).

The two components of agency - internal and external were predicted by a distinctively different set of contextual determinants. Significant predictors of external agency were relatively straightforward, with walking and transportation negatively predicting increases in external agency. This is illustrative of external agency being dependent on objective, environmentally defined, constraints, and activities rather than internal experiences. These effects may be less dependent on the music listening experience itself, as we would expect control over our external world to decrease when traveling through different environments, regardless of music-related variables. Previous studies have looked into the motivations and outcomes of listening to music in situations where there is little or no control over our surroundings, such as traveling (Heye and Lamont, 2010; Skånland, 2013), driving (Dibben and Williamson, 2007), and working in an office environment (Haake, 2011). It has been found that listeners envelop themselves in their personal music, with high levels of attention to the music itself, but also increased awareness of their external environment (cf. "auditory bubble," Bull, 2006; Heye and Lamont, 2010). Listening to music when the external sense of agency is low can be seen as an attempt at managing inner/outer spaces, avoiding stressors from the environment, and self-regulating. Indeed, our results confirm that when initial external agency was low, listeners were more 
TABLE 3 | Structural equation model predictors of agency change.

\begin{tabular}{|c|c|c|c|c|c|}
\hline Outcome & Predictor & $\beta$ & SE & $\beta / S E$ & $p$ \\
\hline \multirow[t]{2}{*}{ External agency change } & Activity: Walking & -0.112 & 0.051 & -2.20 & 0.028 \\
\hline & Activity: On transport & -0.080 & 0.040 & -2.04 & 0.042 \\
\hline \multirow[t]{7}{*}{ Internal agency change } & Initial valence & 0.306 & 0.084 & 3.62 & $<0.001$ \\
\hline & Reason: Enjoyment & 0.200 & 0.085 & 2.37 & 0.018 \\
\hline & Reason: To cope & 0.153 & 0.068 & 2.26 & 0.024 \\
\hline & Reason: Enhance mood & 0.152 & 0.053 & 2.87 & 0.004 \\
\hline & Listening alone & 0.128 & 0.062 & 2.06 & 0.040 \\
\hline & Activity: Studying & -0.113 & 0.046 & -2.49 & 0.013 \\
\hline & Reason: Improve mood & 0.085 & 0.041 & 2.07 & 0.039 \\
\hline \multirow[t]{5}{*}{ Music valence } & Initial valence & 0.310 & 0.105 & 2.95 & 0.003 \\
\hline & Location: Home & 0.160 & 0.072 & 2.23 & 0.026 \\
\hline & Activity: Walking & 0.124 & 0.058 & 2.15 & 0.031 \\
\hline & Activity: Housework & 0.114 & 0.040 & 2.85 & 0.004 \\
\hline & Activity: Studying & 0.108 & 0.049 & 2.22 & 0.026 \\
\hline \multirow[t]{3}{*}{ Music arousal } & Initial valence & 0.322 & 0.105 & 3.05 & 0.002 \\
\hline & Activity: Focussed listening & 0.144 & 0.070 & 2.07 & 0.039 \\
\hline & Activity: Housework & 0.124 & 0.045 & 2.76 & 0.006 \\
\hline \multirow[t]{4}{*}{ Attention to music } & Listening alone & 0.191 & 0.083 & 2.32 & 0.020 \\
\hline & Initial internal agency & 0.186 & 0.089 & 2.09 & 0.037 \\
\hline & Reason: Improve mood & 0.144 & 0.061 & 2.37 & 0.018 \\
\hline & Activity: Housework & 0.120 & 0.049 & 2.46 & 0.014 \\
\hline Familiarity of music & Listening alone & 0.193 & 0.088 & 2.19 & 0.028 \\
\hline \multirow[t]{2}{*}{ Reason: Enjoyment } & Initial arousal & -0.213 & 0.076 & -2.80 & 0.005 \\
\hline & Activity: Going to sleep & -0.146 & 0.043 & -3.42 & 0.001 \\
\hline Reason: Diminish mood & Initial internal agency & -0.210 & 0.095 & -2.21 & 0.027 \\
\hline \multirow[t]{3}{*}{ Reason: Enhance mood } & Initial valence & -0.312 & 0.089 & -3.49 & $<0.001$ \\
\hline & Initial external agency & 0.228 & 0.072 & 3.18 & 0.001 \\
\hline & Initial internal agency & 0.171 & 0.055 & 3.10 & 0.002 \\
\hline \multirow[t]{3}{*}{ Reason: Focus on the music } & Activity: In a car & -0.194 & 0.087 & -2.24 & 0.025 \\
\hline & Initial external agency & -0.169 & 0.085 & -1.99 & 0.047 \\
\hline & Listening alone & 0.163 & 0.065 & 2.49 & 0.013 \\
\hline \multirow[t]{3}{*}{ Reason: For activity } & Activity: Focussed listening & -0.168 & 0.054 & -3.10 & 0.002 \\
\hline & Activity: Eating & -0.126 & 0.032 & -3.92 & $<0.001$ \\
\hline & Activity: Doing nothing & -0.116 & 0.058 & -1.99 & 0.046 \\
\hline Reason: Improve mood & Location: Home & 0.216 & 0.082 & 2.62 & 0.009 \\
\hline Reason: Maintain mood & Activity: Eating & -0.055 & 0.024 & -2.33 & 0.020 \\
\hline \multirow[t]{6}{*}{ Reason: Raise energy } & Location: Traveling & -0.334 & 0.100 & -3.35 & 0.001 \\
\hline & Location: Home & -0.250 & 0.111 & -2.25 & 0.025 \\
\hline & Listening alone & -0.193 & 0.054 & -3.56 & $<0.001$ \\
\hline & Location: Work/school & -0.166 & 0.070 & -2.38 & 0.018 \\
\hline & Activity: On transport & 0.153 & 0.049 & 3.15 & 0.002 \\
\hline & Activity: In a car & 0.110 & 0.049 & 2.25 & 0.024 \\
\hline Reason: Thinking & Activity: Gaming & -0.061 & 0.025 & -2.47 & 0.014 \\
\hline \multirow[t]{5}{*}{ Reason: To cope } & Activity: Walking & 0.166 & 0.082 & 2.03 & 0.043 \\
\hline & Location: Work/ school & 0.145 & 0.057 & 2.53 & 0.011 \\
\hline & Activity: Studying & -0.113 & 0.055 & -2.06 & 0.039 \\
\hline & Activity: Going to sleep & -0.104 & 0.049 & -2.13 & 0.034 \\
\hline & Activity: Eating & -0.088 & 0.024 & -3.73 & $<0.001$ \\
\hline \multirow[t]{4}{*}{ Reason: To relax } & Listening alone & -0.252 & 0.071 & -3.53 & $<0.001$ \\
\hline & Activity: Going to sleep & 0.184 & 0.081 & 2.28 & 0.023 \\
\hline & Activity: Focussed listening & 0.134 & 0.049 & 2.72 & 0.006 \\
\hline & Activity: On transport & -0.128 & 0.038 & -3.32 & 0.001 \\
\hline
\end{tabular}

$\beta$, standardized parameter estimate; SE, standard error; $\beta / S E$, $t$ value associated with the parameter estimate; $p$, two-tailed $p$ value (only <0.05 shown). 
likely to be listening for the reason "to focus on the music." This suggests that if listeners have little control over their external environment, the music itself becomes important to them; they feel the need for the "auditory bubble." The reason for listening "to cope" is of particular relevance here, as it was utilized more frequently by those who were walking, and in turn positively predicted internal agency. Worded as "to cope with a situation," this suggests that listeners were using music to improve their internal mood state to deal with their lack of control over the external situation. Furthermore, previous research using mobile ESM found this specific reason to be related to low valence, low arousal moods, as well as poor emotional health and wellbeing of the listener (Randall and Rickard, 2017b). These external agency findings also resonate with a concept that Krueger calls the musically extended mind (2014). Music can be seen as an external resource that enhances internal abilities, and affords possibilities for action at the affective, physical, and social levels (Krueger, 2011, 2014). In a way, this kind of focused music listening has the potential to alter the external environment and the individual's position in it, thus creating a sense of agency (DeNora, 1999, 2000; Krueger, 2014).

In contrast, change of internal agency was significantly predicted by several mood-related experiences, reasons, and goals - in a word, internal experiences. High initial levels of internal agency also predicted greater attention to music, a direct contrast to external agency: engaged (focused, attentive) listening was predicted by low control of the situation but by high contentment of the internal experience. In general, the fact that internal agency change was positively predicted by specific internal reasons for listening suggests that people intend to use music in certain ways that will change their mood to the way they want it to be. This concept is strongly supported by the music psychology literature (Thayer et al., 1994; DeNora, 1999; Saarikallio, 2011; Van Goethem and Sloboda, 2011; Baltazar and Saarikallio, 2016; Baltazar, 2019), including previous mobile ESM research that has found that emotional reasons for listening on mobile phones are utilized to fulfill specific emotional needs (Randall and Rickard, 2017b). The model results show that when internal agency is low (mood state is not ideal), people more frequently intend to diminish the intensity of their current mood state while when internal agency is high (mood state is ideal), people more frequently intend to enhance the intensity of their current mood state, which in turn predicts an increase of internal agency. Overall, it seems that people deliberately use music to control their internal states and this successfully results in an increased sense of internal agency.

Internal agency change was particularly predicted by positive initial valence and reasons for listening that related to positive mood maintenance or mood repair: entertainment/enjoyment, mood enhancement, mood improvement, and coping. Prior research has identified entertainment and positive mood maintenance as one of the most common motivations for music listening for adolescents and young adults (North et al., 2000; Saarikallio, 2008; Randall and Rickard, 2017b). Entertainment has previously been linked to raising moods while listening to music alone (Saarikallio and Erkkilä, 2007) and to higher wellbeing and lower symptomatology (Gebhardt and von Georgi,
2007; Thomson et al., 2014), and the use of music as a coping resource in general has widely been acknowledged in the recent literature (e.g., Miranda and Claes, 2009; Skånland, 2011; Van Goethem and Sloboda, 2011; Miranda, 2019). Entertainment has been considered a regulation strategy of affect that is more embodied and pleasure-oriented, while coping has been seen more closely linked with mental contemplation and the use of cognitive resources: these two types of listening have been argued to serve as complementary components of affect self-regulation (Baltazar and Saarikallio, 2019). Our results show both aspects being predictive of internal agency change, demonstrating that internal agency can be achieved through both types of affectregulatory acts.

A noteworthy observation is that while mood enhancement was predicted by both high initial internal and external agency, the strongest predictor of mood enhancement actually was low initial valence. This indicates that adolescents sometimes want to enhance their current negative mood. This deliberate maintenance of a negative state through music listening has been identified in previous research and discussed in relation to the concept of "misery-sharing" (Gibson et al., 2000; Zillmann and Vorderer, 2000; Skånland, 2013). Whether the purposeful enhancement of negative mood increases internal agency remains a bit ambiguous: Mood enhancement did predict internal agency. However, the expected positive correlation between valence increase and internal agency increase would indicate that the increase of internal agency relates to mood improvement, not to the enhancement of negative mood. Another noteworthy observation was that internal agency change correlated negatively with mood intensity change. The correlation was relatively low but suggests that decrease of mood intensity may relate to increase of internal agency. Previous research has demonstrated emotional stability as a determinant of affective wellbeing (John and Srivastava, 1999; Tomyn and Cummins, 2011), while adolescence has been characterized by higher emotional intensity and lower stability (e.g., Larson et al., 2002). Due to the low effect size this finding should be interpreted with some caution, but future research on how internal agency may correlate with attempts toward emotional homeostasis might be fruitful for understanding music as agentic mood management.

Overall, our results on internal agency and mood changes might be partly explained by the general reciprocal connection between positive experiences, self-efficacy, and sense of agency. As mentioned previously, self-efficacy is the belief that one is able to achieve a certain goal. This belief is reinforced by positive experiences and, in turn, promotes a sense of agency and action-taking. Thus, a positive initial valence might have fostered the participants' sense of agency on their own feelings. This process is better captured by the correlations observed between agency (internal and external) and changes in mood (valence, especially, but arousal also). Feeling better or feeling more of a certain positive affective state might have been experienced as a successful event by the participants. Generally, experiences of mastery and accomplishment serve as a boost to the adolescents' perception of self-efficacy, which in turn inform the perception of agency in the short-term and foster the development of agency in the medium- and long-term (Bandura, 1982, 2005; 
Zimmermann and Cleary, 2005). Music has been proposed as one resource that successfully leads to feeling empowerment (i.e., the reinforcement of efficacy beliefs; Wallace-DiGarbo and Hill, 2006) and self-enhancement (i.e., the tendency to evaluate oneself positively; Elvers, 2016). Saarikallio et al. (2018) found that power-related emotions (self-determination, independence, daring, freedom, strength, empowerment, rebelliousness, and unconstrained feeling) were the second strongest factor out of six explaining music-related pleasure in the participants' everyday life. According to the authors, the factor power reflects healthfostering experiences and is closely related to the sense of agency given the self-determination and control it implies. The observed relatedness of agency increase with valence increase is a noteworthy addition to the broader literature on music and wellbeing, proposing that agency and mood regulation may serve as dialogical determinants for adaptive and health-fostering music engagement (Saarikallio, 2019a).

Internal agency also increased when the adolescents were listening to music alone. This further solidifies the linkage of internal agency to personal and engaged listening. Furthermore, the act of solitary listening can be seen as an important part of youth development in particular. During youth, solitude becomes a constructive part of daily life, supporting the development toward independence, with solitary music listening emerging as an opportunity for self-exploration and personal mood regulation (Larson, 1995). When listening to music on their own, adolescents often report that they create their own world where they can work their affective material (e.g., Saarikallio and Erkkilä, 2007; Van Goethem and Sloboda, 2011). Music also seems to afford precious possibilities for moving between separation and connectedness (DeNora, 2000; Karlsen, 2011). One might argue that this context (listening alone) fosters their autonomy and agency as important steps and outcomes of their development. In developmental psychology, it has been suggested that agency is the marking factor in healthy paths through adolescent, rather than independence, separation, and autonomy from parents (Beyers et al., 2003). Yet, according to Beyers and colleagues, separation might be a needed step at the onset of adolescence, with the goal of developing as a self-direct and, importantly, connected agent.

In line with the social cognitive theory and agency literature, the two aspects of agency measured in the current study internal and external sense of agency - were correlated, but with relatively low effect size. Both components are closely interconnected in the experience of agency, but, notwithstanding, may fluctuate somehow independently based on the context and on the relevance of internal or external factors in the particular situation (Bandura, 1982, 1989). At this point, it is not possible to discern whether the correlation between the internal and external sense of agency is situated at the goal or at the outcomes level (i.e., were the adolescents seeking to regulate their agency globally or did the change in one aspect of agency foster the change in the other aspect). Further investigation would be needed to explore the internal structure of self-perceived agency in adolescents' daily use of music. Nonetheless, it is noteworthy that the two aspects of agency were related to music listening behaviors in a differentiated manner in terms of the contextual determinants. Even though agency in the context of music education and art programs is commonly addressed as a homogeneous concept, at least in the case of music listening it might be useful to explore separately the sense of agency related to inner mood states and the sense of agency related to the surrounding context.

There are certain limitations to consider when interpreting the current results. Firstly, the study involved the subjective assessment of various internal and emotional states, which may be vulnerable to a range of confounding factors. These issues may be amplified for young adolescents, who may have individual sensitivity issues or difficulty in identifying and reporting their emotional states. This subjective self-reporting may also be susceptible to the somewhat intrusive nature of event-based sampling, which could influence the reported emotions. The concepts of internal and external agency were measured only with single items, thus reflecting a relatively narrow definition of each. While this was necessary in the current study in order to keep the episodes answerable when the same questions were answered several times a day, it would be important to encourage future research to take a more elaborate qualitative approach on the conceptual definition of music-based agency and its potential subcomponents. Furthermore, the timeframe over which changes in these variables were measured was limited to $5 \mathrm{~min}$. The results suggest that this was adequate time to elicit changes in agency, but a longer measurement period in future research would yield further insight into how agency fluctuates over time. Finally, the relatively small sample size of the current study was appropriate for exploring contextual variation between the episodes but did not allow modeling the larger interplay of the musical, individual, and contextual determinants. Collecting larger samples for the inclusion of individual differences or using objective measures for assessing musical content might be interesting avenues for future research.

\section{CONCLUSION}

In conclusion, it appears that music listening can indeed support adolescents' sense of agency in daily life, but this clearly is not a phenomenon that can be averaged across all situations and for all listeners, or even for all subcomponents of agency. Our ESM approach was able to identify particular contextual predictors for the impact of music listening on internal and external agency within the plethora of everyday experiences. As would be expected, External Agency was decreased when listeners were traveling through different environments, either on foot or in transport. In contrast, internal agency was increased when the initial mood of the listener was positive, and also when specific reasons for listening were used, suggesting that this outcome is more dependent on the deliberate use of music to influence mood. Overall, the findings provide pioneering insight into understanding music listening from the perspective of adolescent agency and wellbeing within the complexity of daily experiences.

\section{DATA AVAILABILITY STATEMENT}

The datasets generated for this study are available on request to the corresponding author. 


\section{ETHICS STATEMENT}

The studies involving human participants were reviewed and approved by the University of Jyväskylä Ethics Board. Informed consent from the participants' legal guardian/next of kin was obtained by pressing the accept button in the data collection interface of the mobile phone.

\section{AUTHOR CONTRIBUTIONS}

SS, WR, and MB conceived the study, developed the design, conducted the participant recruitment and data collection, compiled the literature, and wrote the manuscript. SS and MB drafted the items. WR set up the data collection app and

\section{REFERENCES}

Baltazar, M. (2019). "Musical affect regulation in adolescents: a conceptual model," in Handbook of Music and Adolescence, eds K. S. McFerran, P. Derrington, and S. Saarikallio, (Oxford: Oxford University Press).

Baltazar, M., and Saarikallio, S. (2016). Toward a better understanding and conceptualization of affect self-regulation through music: a critical, integrative literature review. Psychol. Music 44, 1500-1521. doi: 10.1177/ 0305735616663313

Baltazar, M., and Saarikallio, S. (2019). Strategies and mechanisms in musical affect self-regulation: a new model. Musicae Sci. 23, 177-195. doi: 10.1177/ 1029864917715061

Bandura, A. (1977). Self-efficacy: toward a unifying theory of behavioral change. Psychol. Rev. 84, 191-215. doi: 10.1037/0033-295X.84.2.191

Bandura, A. (1982). Self-efficacy mechanism in human agency. Am. Psychol. 37, 122-147. doi: 10.1016/0006-8993(86)91535-0

Bandura, A. (1989). Human agency in social cognitive theory. Am. Psychol. 44, 1175-1184. doi: 10.1037/0003-066X.44.9.1175

Bandura, A. (2005). "Adolescent development from an agentic perspective," in SelfEfficacy Beliefs of Adolescents ebook, eds T. C. Urdan, and F. Pajares, (Charlotte, NC: Information Age Publishing), 1-43. doi: 10.1016/j.jbusvent.2009.07.006

Bandura, A. (2006). Toward a psychology of human agency. Perspect. Psychol. Sci. 1, 164-180. doi: 10.1111/j.1745-6916.2006.00011.x

Bandura, A. Ed. (1995). Self-Efficacy in Changing Societies. Cambridge: Cambridge University Press.

Batt-Rawden, K., and DeNora, T. (2005). Music and informal learning in everyday life. Music Educ. Res. 7, 289-304. doi: 10.1080/14613800500324507

Batt-Rawden, K., DeNora, T., and Ruud, E. (2005). Music listening and empowerment in health promotion: a study of the role and significance of music in everyday life of the long-term III. Nordic J. Music Ther. 14, 120-136. doi: 10.1080/08098130509478134

Batt-Rawden, K., and Tellnes, G. (2011). How music may promote healthy behaviour. Scand. J. Public Health 39, 113-120. doi: 10.1177/1403494810393555

Bernatzky, G., Presch, M., Anderson, M., and Panksepp, J. (2011). Emotional foundations of music as a non-pharmacological pain management tool in modern medicine. Neurosci. Biobehav. Rev. 35, 1989-1999. doi: 10.1016/j. neubiorev.2011.06.005

Beyers, W., Goossens, L., Vansant, I., and Moors, E. (2003). A structural model of autonomy in middle and late adolescence: connectedness, separation, detachment, and agency. J. Youth Adolesc. 32, 351-365. doi: 10.1023/A: 1024922031510

Bonsdorff, P. V. (2017). "Transformations of the everyday: the social aesthetics of childhood," in Ästhetiken in Kindheit und Jugend : Sozialisation im Spannungsfeld von Kreativität, Konsum und Distinktion, eds S. Schinkel, and I. Herrmann, (Bielefeld: transcript Verlag), 319-334. doi: 10.14361/ 9783839434833-018

Bosmans, M. W. G., and van der Velden, P. G. (2015). Longitudinal interplay between posttraumatic stress symptoms and coping self-efficacy: a four-wave conducted the data analyses. SS and WR acquired the ethical clearance. All authors reviewed and approved the final version of the manuscript.

\section{FUNDING}

This study was funded by the Academy of Finland (project number 316912).

\section{ACKNOWLEDGMENTS}

The authors would like to thank Essi Asikainen and Reetta Honkavuori for helping in data collection.

prospective study. Soc. Sci. Med. 134, 23-29. doi: 10.1016/j.socscimed.2015. 04.007

Bull, M. (2006). "Investigating the culture of mobile listening: from Walkman to iPod," in Consuming Music Together: Social and Collaborative Aspects of Music Consumption Technologies, eds K. O’Hara, and B. Brown, (London: Springer), 131-149. doi: 10.1007/1-4020-4097-0_7

Côté, J. E., and Schwartz, S. J. (2002). Comparing psychological and sociological approaches to identity: identity status, identity capital, and the individualization process. J. Adolesc. 25, 571-586. doi: 10.1006/jado.2002.0511

DeNora, T. (1999). Music as a technology of the self. Poetics 27, 31-56. doi: 10. 1016/S0304-422X(99)00017-0

DeNora, T. (2000). Music in Everyday Life. Cambridge: Cambridge University Press.

DeNora, T. (2001). "Aesthetic agency and musical practice: new directions in the sociology of music and emotion," in Music and Emotion: Theory and Research, eds P. N. Juslin, and J. A. Sloboda, (Oxford: Oxford University Press), 161-180.

DeNora, T. (2013). Music Asylums: Wellbeing Through Music in Everyday Life. Farnham: Ashgate.

Dibben, N., and Williamson, V. J. (2007). An exploratory survey of in-vehicle music listening. Psychol. Music 35, 571-589. doi: 10.1177/030573560707 9725

Elvers, P. (2016). Songs for the ego: theorizing musical self-enhancement. Front. Psychol. 7:2. doi: 10.3389/fpsyg.2016.00002

Esser, F., Baader, M. S., Betz, T., and Hungerland, B. eds (2016). Reconceptualising Agency and Childhood: New Perspectives in Childhood Studies. Abingdon: Routledge, doi: 10.4324/9781315722245

Gebhardt, S., and von Georgi, R. (2007). Music, mental disorder and emotional reception behavior. Music Ther. Today 8, 419-445.

Gibson, R., Aust, C. F., and Zillmann, D. (2000). Loneliness of adolescents and their choice and enjoyment of love-celebrating versus love-lamenting popular music. Empir. Stud. Arts 18, 43-48. doi: 10.2190/b51g-8u0w-n0eq-mjuu

Gold, C., Saarikallio, S., and McFerran, K. S. (2011). "Music therapy," in Encyclopedia of Adolescence, ed. R. J. R. Levesque, (New York, NY: Springer), 1-12. doi: 10.1007/978-1-4419-1695-2

Gowers, S. (2005). Development in adolescence. Psychiatry 4, 6-9. doi: 10.1383/ psyt.4.6.6.66353

Haake, A. B. (2011). Individual music listening in workplace settings: an exploratory survey of offices in the UK. Musicae Sci. 15, 107-129. doi: 10.1177/ 1029864911398065

Hektner, J. M., Schmidt, J. A., and Csikszentmihalyi, M. (2007). Experience Sampling Method: Measuring the Quality of Everyday Life. Thousand Oaks, CA: Sage.

Hense, C., and McFerran, K. S. (2017). Promoting young people's musical identities to facilitate recovery from mental illness. J. Youth Stud. 20, 997-1012. doi: $10.1080 / 13676261.2017 .1287888$

Heye, A., and Lamont, A. (2010). Mobile listening situations in everyday life: the use of MP3 players while travelling. Musicae Sci. 14, 95-120. doi: 10.1177/ 102986491001400104 
Hu, L. T., and Bentler, P. M. (1999). Cutoff criteria for fit indexes in covariance structure analysis: conventional criteria versus new alternatives. Struc. Equ. Model. 6, 1-55. doi: 10.1080/10705519909540118

Jiang, J., Zhou, L., Rickson, D., and Jiang, C. (2013). The effects of sedative and stimulative music on stress reduction depend on music preference. Arts Psychother. 40, 201-205. doi: 10.1016/j.aip.2013. 02.002

John, O. P., and Srivastava, S. (1999). "The Big-Five trait taxonomy: history, measurement, and theoretical perspectives," in Handbook of Personality: Theory and Research, Vol. 2, eds L. A. Pervin, and O. P. John, (New York, NY: Guilford Press), 102-138.

Karlsen, S. (2011). Using musical agency as a lens: researching music education from the angle of experience. Res. Stud. Music Educ. 33, 107-121. doi: 10.1177/ $1321103 \times 11422005$

Krueger, J. (2011). Doing things with music. Phenomenol. Cogn. Sci. 10, 1-22. doi: 10.1007/s11097-010-9152-4

Krueger, J. (2014). Affordance and the musically extended mind. Front. Psychol. 4:1003. doi: 10.3389/fpsyg. 2013.01003

Krueger, J. (2018). "Music as affective scaffolding," in Music and Consciousness II: Philosophical, Psychological, and Cultural Perspectives, eds D. Clarke, R. Herbert, and E. Clarke, (Oxford: Oxford University Press).

Kuuse, A. (2018). "We will fight Goliath": negotiation of space for musical agency in children's music education. Res. Stud. Music Educ. 40, 140-156. doi: 10.1177/ $1321103 \times 18771796$

Laiho, S. (2004). The psychological functions of music in adolescence. Nordic J. Music Ther. 13, 47-63. doi: 10.1080/08098130409478097

Larson, R. (1995). Secrets in the bedroom: adolescents' private use of media. J. Youth Adolesc. 24, 535-549.

Larson, R. W., Moneta, G., Richards, M. H., and Wilson, S. (2002). Continuity, stability, and change in daily emotional experience across adolescence. Child Dev. 73, 1151-1165. doi: 10.1111/1467-8624.00464

Leipold, B., and Loepthien, T. (2015). Music reception and emotional regulation in adolescence and adulthood. Musicae Sci. 19, 111-128. doi: 10.1177/ 1029864915570354

Lerner, R. M., Freund, A. M., De Stefanis, I., and Habermas, T. (2001). Understanding developmental regulation in adolescence: the use of the selection, optimization, and compensation model. Hum. Dev. 44, 29-50. doi: $10.1159 / 000057039$

Lillevoll, K. R., Kroger, J., and Martinussen, M. (2013). Identity status and locus of control: a meta-analysis. Identity 13, 253-265. doi: 10.1080/15283488.2013. 799471

Lincoln, S. (2005). Feeling the noise: teenagers, bedrooms and music. Leisure Stud. 24, 399-414. doi: 10.1080/02614360500199544

Magee, W. L. (2017). "Music-making in therapeutic contexts: reframing identity following disruptions to health," in Handbook of Musical Identities, eds R. MacDonald, D. J. Hargreaves, and D. Miell, (New York, NY: Oxford University Press), 624-641. doi: 10.1093/acprof:oso/9780199679485.003. 0034

Martin, J., Sugarman, J., and Thompson, J. (2003). Psychology and the Question of Agency. Albany, NY: SUNY Press.

McFerran, K. S. (2011). "Music and adolescents," in Lifelong Engagement with Music: Benefits for Mental Health and Well-Being, eds N. S. Rickard, and K. S. McFerran, (Hauppauge, NY: Nova Science Publishers), 97-108.

McFerran, K. S., Hense, C., Koike, A., and Rickwood, D. (2018). Intentional music use to reduce psychological distress in adolescents accessing primary mental health care. Clin. Child Psychol. Psychiatry 23, 567-581. doi: 10.1177/ 1359104518767231

McFerran, K. S., and Saarikallio, S. (2014). Depending on music to feel better: being conscious of responsibility when appropriating the power of music. Arts Psychother. 41, 89-97. doi: 10.1016/j.aip.2013.11.007

Miranda, D. (2013). The role of music in adolescent development: much more than the same old song. Int. J. Adolesc. Youth 18, 5-22. doi: 10.1080/02673843.2011. 650182

Miranda, D. (2019). A review of research on music and coping in adolescence. Psychomusicology 29, 1-9. doi: 10.1037/pmu0000229

Miranda, D., and Claes, M. (2009). Music listening, coping, peer affiliation and depression in adolescence. Psychol. Music 37, 215-233. doi: 10.1177/ 0305735608097245
Mitchell, L. A., and Macdonald, R. A. R. (2006). An experimental investigation of the effects of preferred and relaxing music listening on pain perception. J. Music Ther. 43, 295-316. doi: 10.1093/jmt/43.4.295

Muthén, L. K., and Muthén, B. O. (2015). Mplus User's Guide, 7th Edn. Los Angeles, CA: Muthén \& Muthén.

North, A. C., and Hargreaves, D. J. (1999). Music and adolescent identity. Music Educ. Res. 1, 75-92. doi: 10.1080/1461380990010107

North, A. C., Hargreaves, D. J., and O'Neill, S. A. (2000). The importance of music to adolescents. Br. J. Educ. Psychol. 70, 255-272. doi: 10.1348/000709900158083

O'Neill, S. A. (2017). "Young people's musical lives: learning ecologies, identities, and connectedness," in Handbook of Musical Identities, eds R. MacDonald, D. J. Hargreaves, and D. Miell, (New York, NY: Oxford University Press), 79-104. doi: 10.1093/acprof:oso/9780199679485.003.0005

Pajares, F. (2005). "Self-efficacy during childhood and adolescent: implications for teachers and parents," in Self-Efficacy Beliefs of Adolescents ebook, eds T. C. Urdan, and F. Pajares, (Charlotte, NC: Information Age Publishing), 339-367.

Pajares, F., and Urdan, T. eds (2006). Self(-)Efficacy Beliefs of Adolescents (ebook). Greenwich: Information Age Publishing.

Papinczak, Z. E., Dingle, G. A., Stoyanov, S. R., Hides, L., and Zelenko, O. (2015). Young people's uses of music for well-being. J. Youth Stud. 18, 1119-1134. doi: 10.1080/13676261.2015.1020935

Pothoulaki, M., MacDonald, R. A. R., Flowers, P., Stamataki, E., Filiopoulos, V., Stamatiadis, D., et al. (2008). An investigation of the effects of music on anxiety and pain perception in patients undergoing haemodialysis treatment. J. Health Psychol. 13, 912-920. doi: 10.1177/1359105308095065

Randall, W. M., and Rickard, N. S. (2013). Development and trial of a music experience sampling method (m-ESM) for personal music listening. Music Percept. 31, 157-170. doi: 10.1525/mp.2013.31.2.157

Randall, W. M., and Rickard, N. S. (2017a). Personal music listening: a model of emotional outcomes developed through mobile experience sampling. Music Percept. 34, 501-514. doi: 10.1525/mp.2017.34.5.501

Randall, W. M., and Rickard, N. S. (2017b). Reasons for personal music listening: a mobile experience sampling study of emotional outcomes. Psychol. Music 45, 479-495. doi: 10.1177/0305735616666939

Randall, W. M., Rickard, N. S., and Vella-Brodrick, D. A. (2014). Emotional outcomes of regulation strategies used during personal music listening: a mobile experience sampling study. Musicae Sci. 18, 275-291. doi: 10.1177/ 1029864914536430

Rissanen, M. (2017). "It's as if..." Preschoolers encountering contemporary photography. Int. J. Educ. Arts 18, 2-31.

Ryan, R. M., and Deci, E. L. (2000). Self-determination theory and the facilitation of intrinsic motivation, social development, and well-being. Am. Psychol. 55, 68-78. doi: 10.1037/0003-066X.55.1.68

Saarikallio, S. (2008). Music in mood regulation: initial scale development. Musicae Sci. 12, 291-309. doi: 10.1371/journal.pone.0211362

Saarikallio, S. (2011). Music as emotional self-regulation throughout adulthood. Psychol. Music 39, 307-327. doi: 10.1177/0305735610374894

Saarikallio, S. (2017). "Musical identity in fostering emotional health," in Handbook of Musical Identities, eds R. Macdonald, D. J. Hargreaves, and D. Miell, (Oxford: Oxford University Press), 602-623. doi: 10.1093/acprof:oso/9780199679485. 003.0033

Saarikallio, S. (2019a). Access-Awareness-Agency (AAA) model of music-based social-emotional competence (MuSEC). Music Sci. 2, 1-16. doi: 10.1177/ 2059204318815421

Saarikallio, S. (2019b). "Music \& identity: agency \& empowerment," in Handbook of Music, Adolescents, and Wellbeing, eds K. McFerran, P. Derrington, and S. Saarikallio, (Oxford: Oxford University Press).

Saarikallio, S., and Baltazar, M. (2018). "Music as a forum for social-emotional health," in Music and Public Health: A Nordic Perspective, eds L. O. Bonde, and T. Theorell, (New York, NY: Springer International Publishing), 101-113. doi: 10.1007/978-3-319-76240-1

Saarikallio, S., and Erkkilä, J. (2007). The role of music in adolescents' mood regulation. Psychol. Music 35, 88-109. doi: 10.1177/0305735607068889

Saarikallio, S., Maksimainen, J., and Randall, W. M. (2018). Relaxed and connected: insights into the emotional-motivational constituents of musical pleasure. Psychol. Music 47, 644-662. doi: 10.1177/0305735618778768

Sawatzky, R. G., Ratner, P. A., Richardson, C. G., Washburn, C., Sudmant, W., and Mirwaldt, P. (2012). Stress and depression in students: the mediating role 
of stress management self-efficacy. Nurs. Res. 61, 13-21. doi: 10.1097/NNR. 0b013e31823b1440

Schnoll, R. A., Martinez, E., Tatum, K. L., Glass, M., Bernath, A., Ferris, D., et al. (2011). Increased self-efficacy to quit and perceived control over withdrawal symptoms predict smoking cessation following nicotine dependence treatment. Addict. Behav. 36, 144-147. doi: 10.1016/j.addbeh.2010.08.024

Schwartz, K. D., and Fouts, G. T. (2003). Music preferences, personality style, and developmental issues of adolescents. J. Youth Adolesc. 32, 205-213. doi: 10.1023/a:1022547520656

Schwartz, S. J., Cote, J. E., and Arnett, J. (2005). Identity and agency in emerging adulthood: two developmental routes in the individualization process. Youth Soc. 37, 201-229. doi: 10.1177/0044118x05275965

Selfhout, M. H. W., Branje, S. J. T., ter Bogt, T. F. M., and Meeus, W. H. J. (2009). The role of music preferences in early adolescents' friendship formation and stability. J. Adolesc. 32, 95-107. doi: 10.1016/j.adolescence.2007.11.004

Skånland, M. S. (2011). Use of mp3-players as a coping resource. Music Arts Act. 3, 15-33.

Skånland, M. S. (2013). Everyday music listening and affect regulation: the role of MP3 players. Int. J. Qual. Stud. Health Well-Being 8:20595. doi: 10.3402/qhw. v8i0.20595

Strecher, V. J., Mcevoy Devellis, B., Becker, M. H., and Rosenstock, I. M. (1986). The role of self-efficacy in achieving health behavior change. Health Educ. Q. 13, 73-92. doi: 10.1177/109019818601300108

ter Bogt, T. F. M., Soitos, S., and Delsing, M. (2012). "Music listening in adolescence," in Encyclopedia of Adolescence, Vol. 1, ed. R. J. R. Levesque, (Amsterdam: Elsevier), 240-250. doi: 10.1016/B978-0-12-37395-5.00 029-2

ter Bogt, T. F. M., Vieno, A., Doornwaard, S. M., Pastore, M., and van den Eijnden, R. J. J. M. (2017). "You're not alone": music as a source of consolation among adolescents and young adults. Psychol. Music 45, 155-171. doi: 10.1177/ 0305735616650029

Thayer, R. E., Newman, J. R., and McClain, T. M. (1994). Self-regulation of mood: strategies for changing a bad mood, raising energy, and reducing tension. J. Pers. Soc. Psychol. 67, 910-925. doi: 10.1037//0022-3514.67.5.910

Thoma, M. V., Ryf, S., Mohiyeddini, C., Ehlert, U., and Nater, U. M. (2012). Emotion regulation through listening to music in everyday situations. Cogn. Emot. 26, 550-560. doi: 10.1080/02699931.2011.595390
Thomson, C. J., Reece, J. E., and Di Benedetto, M. (2014). The relationship between music-related mood regulation and psychopathology in young people. Musicae Sci. 18, 150-165. doi: 10.1177/102986491452 1422

Tomyn, A. J., and Cummins, R. A. (2011). Subjective wellbeing and homeostatically protected mood: theory validation with adolescents. J. Happiness Stud. 12, 897-914. doi: 10.1007/s10902-010-9235-5

Van Goethem, A., and Sloboda, J. A. (2011). The functions of music for affect regulation. Musicae Sci. 15, 208-228. doi: 10.1177/102986491140 1174

Vuoskoski, J., and Eerola, T. (2011). Measuring music-induced emotion: a comparison of emotion models, personality biases, and intensity of experiences. Musicae Sci. 15, 159-173. doi: 10.1177/1029864911403367

Wallace-DiGarbo, A., and Hill, D. C. (2006). Art as agency: exploring empowerment of at-risk youth. J. Am. Art Ther. Assoc. 23, 119-125. doi: 10. 1080/07421656.2006.10129627

Wiggins, J. (2016). "Musical agency," in The Child as Musician: A Handbook of Musical Development, 2nd Edn, ed. G. E. McPherson, (St. Ives: Oxford University Press), 102-121. doi: 10.1093/acprof:oso/9780198744443.003. 0006

Zillmann, D., and Vorderer, P. (2000). Media Entertainment: The Psychology of Its Appeal. Mahwah, NJ: Lawrence Erlbaum.

Zimmermann, B. J., and Cleary, T. J. (2005). “Adolescents' development of personal agency: the role of self-efficacy beliefs and self-regulatory skill," in Self-Efficacy Beliefs of Adolescents ebook, eds T. C. Urdan, and F. Pajares, (Charlotte, NC: Information Age Publishing), 45-69.

Conflict of Interest: The authors declare that the research was conducted in the absence of any commercial or financial relationships that could be construed as a potential conflict of interest.

Copyright (C) 2020 Saarikallio, Randall and Baltazar. This is an open-access article distributed under the terms of the Creative Commons Attribution License (CC BY). The use, distribution or reproduction in other forums is permitted, provided the original author(s) and the copyright owner(s) are credited and that the original publication in this journal is cited, in accordance with accepted academic practice. No use, distribution or reproduction is permitted which does not comply with these terms. 